\title{
Peningkatan Produktivitas Tanaman Padi Sawah Melalui Pemupukan Kompos dan NPK
}

\author{
I GUSTI PUTU RATNA ADI*) DAN I NYOMAN PUJA
}

\author{
Program Studi Agroekoteknologi Fakultas Pertanian Universitas Udayana, \\ ${ }^{*}$ E-mail: ratnaadi@gmail.com
}

\begin{abstract}
Increased Rice Crop Productivity Through Compost and NPK Fertilization. The aims of this research was to study response of compost and NPK fertilizers to the soil chemical properties and rice yield. The method used was a factorial Randomized Block Design consisting of two factors. The first factor was compost Fertilizer (B) consists of 2 levels, namely: $\mathrm{B}_{0}=$ Without compost fertilizer and $\mathrm{B}_{1}=5$ ton compost fertilizer ha $\mathrm{a}^{-1}$. The second factors was NPK national recomendation $(\mathrm{P})$ consists of 3 levels, namely: $\mathrm{P}_{1}=50 \%$ of NPK recommendation, $\mathrm{P}_{2}=100 \%$ of NPK recommendation and $\mathrm{P}_{3}=$ $150 \%$ of NPK recommendation. The results showed that the treatment of compost and NPK fertilizers gave no significant effect on tillers number clumb ${ }^{-1}$ and dry straw weight $/ \mathrm{m}^{2}$, but gave a significant effect on $\mathrm{N}, \mathrm{P}, \mathrm{K}$ and dry grain weight $/ \mathrm{m}^{2}$. The combination of 5 tons of compost/ha and $150 \%$ of NPK recommendation can produce N-total, P-available level, Kavailable and dry grain weight per $\mathrm{m}^{2}$ respectively $0.35 \%, 13.79 \mathrm{ppm}, 355,21 \mathrm{ppm}$ and 0.96 $\mathrm{kg}$ and significantly higher than the combination of $50 \%$ NPK recommendation and without compost, which were $0.26 \%, 8.21 \mathrm{ppm}, 236.10 \mathrm{ppm}$ and $0.69 \mathrm{~kg}$ respectively.
\end{abstract}

Keywords: Compost, NPK, productivitas, and rice

\section{PENDAHULUAN}

Penduduk Indonesia terus bertambah setiap tahun membutuhkan bahan pangan yang terus meningkat karena jumlah penduduk berhubungan langsung dengan penyediaan pangan. Sektor pertanian yang berperanan untuk memenuhi kebutuhan penduduk menjadi tantangan untuk menyediakan kebutuhan akan pangan utamanya beras karena bahan makanan pokok penduduk Indonesia adalah beras. Usaha peningkatan produksi padi di Indonesia terus dikembangkan secara berkelanjutan melalui peningkatan kesuburan tanah dan produktivitas padi. Rachmat et al. (2008) menyatakan bahwa kesuburan tanah adalah suatu keadaan tanah dimana tata air, udara dan unsur hara dalam keadaan cukup, seimbang dan tersedia sesuai dengan kebutuhan tanaman. Usaha untuk memenuhi 
I GUSTI PUTU RATNA ADI DAN I NYOMAN PUJA. Peningkatan Produktivitas Tanaman Padi...

kecukupan unsur hara dalam tanah dapat dilakukan dengan pemupukan. Kasniari dan Supadma (2007) menyatakan pemupukan merupakan salah satu faktor penentu di dalam upaya meningkatkan produktivitas pangan. Pupuk adalah bahan yang dimasukan kedalam tanah dengan tujuan mengubah sifat fisik, kimia dan biologi tanah sehingga menjadi lebih baik untuk pertumbuhan tanaman (Yowono dan Rosmarkam, 2002). Kecendrungan petani saat ini dalam usaha budidaya tanaman adalah menggunakan pupuk anorganik (kimia) dengan alasan praktis. Kaya (2014) menyatakan bahwa pada lahan sawah intensif menunjukkan sebagian besar tanaman padi sudah tidak tanggap terhadap pemupukan $\mathrm{P}$ dan $\mathrm{K}$ anorganik, karena pemberian pupuk anorganik kelarutannya dalam tanah sanga lambat sehingga dapat merusak lingkungan. Selanjnya Wahyuni et al. (2015) kebutuhan pupuk $\mathrm{N}, \mathrm{P}$ dan $\mathrm{K}$ dari tahun-ke tahun mengalami peningkatan. Untuk mengurangi perbedaan yang besar dibutuhkan tambahan pupuk organik dan hayati.

Selain menggunakan pupuk anorganik, upaya lain dapat dilakukan untuk memperbaiki kesuburan tanah adalah menggunakan pupuk organik. Salah satu pupuk organik yang dapat digunakan adalah kompos yang dapat dibuat dari dengan bahan baku yang tersedia di lokasi setempat seperti jerami, limbah ternak peliharaan atau limbah pertanian lainnya. Menurut Rachman et al. (2008) pupuk organik berfungsi meningkatkan kandungan bahan organik tanah, memberikan kontribusi ketersediaan hara $\mathrm{N}, \mathrm{P}, \mathrm{K}$ dan mengifisienkan penggunaan pupuk anorganik (pabrik). Selanjutnya ditambahkan bahan organik kedalam tanah sangat membantu dalam memperbaiki tanah yang telah terdegradasi karena bahan organik dapat mengikat unsur hara yang mudah hilang dan membantu menyediakan unsur hara tanah. Penggunaan pupuk organik saat ini sudah menjadi perhatian dari segi lingkungan dan keinginan meniadakan atau mengurangi akibat negatif yang ditimbulkan oleh penggunaan pupuk kimiawi (kimiawi). Disamping hal tersebut, masyarakat mulai menginginkan mengkomsumsi produk pertanian yang sehat dan berkualitas, sehingga mendorong berkembangnya produk pertanian organik, sekalipun harganya lebih mahal.

Berdasarkan uraian di atas telah dilaksanakan penelitian ini dengan tujuan untuk mengetahui pengaruh pupuk kompos dan NPK terhadap sifat kimia tanah dan hasil tanaman padi. Hasil penelitian ini diharapkan dapat dipakai sebagai pedoman oleh petani dan pengambil kebijakan dalam usaha 
budidaya tanaman padi dalam rangka dan insektisida. Alat yang digunakan pada meningkatkan produktivitas padi secara penelitian ini adalah cangkul, traktor, berkelanjutan.

timbangan, arit, meteran, oven dan timbangan. Pupuk organik yang digunakan

\section{METODE PENELITIAN}

Penelitian ini dilaksanakan pada bulan Mei sampai dengan Oktober 2018.pada lahan sawah di Subak Tirta Jati, Desa Buahan Kaja, Kabupaten Gianyar. Analisis tanah dilakukan di Laboratorium Tanah dan Lingkungan Fakultas Pertanian Universitas Udayana adalah kompos limbah ternak sapi yang diproduksi oleh kelompok tani Putra Yasa, Desa Tenganan, Kecamatan Manggis, Kabupaten Karangasem. Bahan kompos adalah limbah ternak sapi, serbuk gergaji yang dipermentasi dengan bantuan mikroba probiotik. Kandungan unsur haran kompos limbah ternak sapi disajikan pada Tabel 1.

Bahan yang digunakan terdiri dari kompos limbah ternak sapi, benih padi varietas IR64, pupuk Ponska, Urea, pestisida

Tabel 1. Kandungan unsur hara kompos Limbah Ternak

\begin{tabular}{llcl}
\hline No & Unsur hara & Kandungan & Keterangan \\
\hline 1 & Kadar air $(\%)$ & 48,80 & - \\
2 & pH & 7,2 & Basa \\
3 & C-organik $(\%)$ & 8,7 & Sangat tinggi \\
4 & N $(\%)$ & 0,4 & Sangat tinggi \\
5 & C/N & 18 & Sangat tinggi \\
6 & P2O5 (\%) & 0,38 & Sangat tinggi \\
7 & K2O (\%) & 1,17 & Sangat tinggi \\
8 & Ca-dd & 2,44 & Sangat tinggi \\
\hline
\end{tabular}

Sumber : Hasil analisis hara di laboratorium

Penelitian ini menggunakan taraf : $\mathrm{P}_{1}=50 \%$ Rekomendasi NPK (100 Rancangan Acak Kelompok (RAK) faktorial $\mathrm{kg}$ Ponska $+100 \mathrm{~kg}$ Urea $/ \mathrm{ha}, \quad \mathrm{P}_{2}=100 \%$ terdiri atas dua faktor yaitu :1) Pupuk Rekomendasi NPK (200 kg Ponska + $200 \mathrm{~kg}$ Kompos (B) terdiri atas 2 taraf yaitu : $\mathrm{B}_{0}=$ Urea)/ha dan $\mathrm{P}_{3}=150 \%$ Rekomendasi NPK Tanpa pupuk kompos dan $\mathrm{B}_{1}=5$ ton pupuk $(300 \mathrm{~kg}$ Ponska $+300 \mathrm{~kg}$ Urea $/ \mathrm{ha}$. kompos/ha. 2) Pupuk NPK (P) terdiri atas 3 Perlakuan kombinasi menjadi 6 perlakuan 
I GUSTI PUTU RATNA ADI DAN I NYOMAN PUJA. Peningkatan Produktivitas Tanaman Padi...

yaitu : $\mathrm{B}_{0} \mathrm{P}_{1}, \mathrm{~B}_{0} \mathrm{P}_{2}, \mathrm{~B}_{0} \mathrm{P}_{3}, \mathrm{~B}_{1} \mathrm{P}_{1}, \mathrm{~B}_{1} \mathrm{P}_{2}$ dan $\mathrm{B}_{1} \mathrm{P}_{3}$ meliputi penyiangan secara manual, dan masing-masing perlakuan diulang pengairan menggunakan air irigasi, sebanyak 4 kali sehingga terdapat 24 petak pemberantasan hama dan penyakit digunakan penelitian. secara kimiawi.

Parameter yang diamati terdiri atas

\section{Pelaksanaan Penelitian}

Tanah yang digunakan tempat penelitian dibersihkan dari gulma dan sisa kotoran lainnya, kemudian tanah diolah dengan cangkul pada seluruh permukaan tanah dan digaru sampai rata- Bedengan dibuat dengan ukuran $6 \mathrm{~m}$ x $8 \mathrm{~m}$ dan jarak antara bedengan $50 \mathrm{~cm}$ yang berfungsi saluran drainase.

Aplikasi pupuk kompos dilakukan dua hari sebelum tanam dengan cara menyebar secara merata pada petak sesuai dengan perlakuan. Aplikasi pupuk NPK dilakukan 3 kali yaitu pemupukan 1 pada umur satu minggu setelah tanam (MST) dengan dosis $30 \%$ dosis Urea dan $50 \%$ Ponska, pemupukan II umur 4 MST dengan dosis 40 $\%$ dosis Urea dan pemupukan III dilakukan pada umur 8 MST dengan dosis $30 \%$ urea dan $50 \%$ dosis Ponska. Pemupukan dilakukan dengan cara ditebar secara merata di seluruh permukaan tanah. Penanaman dilakukan dengan sistem tanam pindah menggunakan bibit berumur 21 hari. Cara penanaman dilakukan dengan sistem jajar legowo 2 : 1 . Pemeliharaan tanaman sifat kimia dan tanaman, sifat kimia tanah adalah kadar $\mathrm{N}$ dengan metode Kjeldhal, kadar $\mathrm{P}$ dan $\mathrm{K}$ dengan metode Pengekstrak $\mathrm{HCl} 25 \%$. Parameter tanaman adalah jumlah anakan/rumpun, berat jerami kering per $\mathrm{m} 2$ dan berat gabah berisi kering per $\mathrm{m} 2$.

\section{HASIL DAN PEMBAHASAN Parameter Sifat Kimia Tanah}

Berdasarkan hasil analisis statistik menunjukkan bahwa pemberian perlakuan pupuk kompos dan NPK memberikan pengaruh yang nyata sampai sangat nyata terhadap kadar N, P, K dan berat gabah berisi kering per $\mathrm{m}^{2}$. Pengaruh pupuk kompos dan NPK terhadap sifat kimia tanah $\mathrm{N}, \mathrm{P}, \mathrm{K}$ disajikan pada Tabel 2.

\section{Kadar N-Total Tanah}

Perlakuan pupuk Kompos (B) dan NPK (P) memberikan pengaruh yang nyata terhadap kadar N-total, disebabkan pupuk kompos dan NPK masing-masing memberikan sumbangan hara $\mathrm{N}$ kedalam tanah, sehingga kandungan $\mathrm{N}$ dalam tanah menjadi meningkat. Pupuk Urea yang digunakan memberikan sumbangan hara $\mathrm{N}$ sebanyak 
46\% dan pupuk NPK-Ponska $15 \%$ dari dosis yang diberikan. Demikian juga berdasarkan hasil analisis pupuk Kompos memberikan sumbangan unsur $\mathrm{N}$ ke dalam tanah sebanyak 0,4\% dari dosis pupuk Kompos. Hal ini dapat dilihat dari hasil pengamatan perlakuan kombinasi pupuk kompos dan $150 \%$ rekomendasi NPK memberikan kadar N-total tanah tertinggi yaitu $0,35 \%$ dan terendah pada $50 \%$ rekomendasi NPK dan tanpa kompos $(0,26 \%)$. Hasil penelitian ini sesuai dengan hasil penelitian Hermawan, (2002; dalam Rachman et al, 2008) bahwa pemberian bahan organik dan pupuk anorganik dapat meningkatkan N-total, Ptersedia dan K-tersedia di dalam tanah.

Tabel 2. Pengaruh Pupuk Kompos dan Pupuk NPK terhadap Sifat Kimia Tanah

\begin{tabular}{cccc}
\hline \multirow{2}{*}{ Perlakuan } & \multicolumn{3}{c}{ Parameter Sifat Kimia Tanah } \\
\cline { 2 - 4 } & N-Total (\%) & P-Terseda $(\mathrm{ppm})$ & K-Tersedia $(\mathrm{ppm})$ \\
\hline Pupuk Organik & $0,28 \mathrm{a}$ & $9,59 \mathrm{a}$ & $267.81 \mathrm{a}$ \\
$\mathrm{B}_{0}$ & $0,33 \mathrm{~b}$ & $11,04 \mathrm{~b}$ & $320.56 \mathrm{~b}$ \\
$\mathrm{~B}_{1}$ & $\mathbf{0 , 0 2}$ & $\mathbf{1 , 5 2}$ & $\mathbf{1 9 , 4 8}$ \\
\hline BNT 5 \% & & & \\
\hline Pupuk Anorganik & $0.29 \mathrm{a}$ & $8,33 \mathrm{a}$ & $247.85 \mathrm{a}$ \\
$\mathrm{P}_{1}$ & $0.30 \mathrm{~b}$ & $9,68 \mathrm{a}$ & $296.23 \mathrm{~b}$ \\
$\mathrm{P}_{2}$ & $0.33 \mathrm{c}$ & $12,93 \mathrm{~b}$ & $338.49 \mathrm{c}$ \\
$\mathrm{P}_{3}$ & $\mathbf{0 . 2}$ & $\mathbf{1 . 8 6}$ & $\mathbf{2 3 . 8 6}$ \\
\hline BNT 5 \% & & & \\
Interaksi B x P & $0,26 \mathrm{a}$ & $8,21 \mathrm{a}$ & $236,10 \mathrm{a}$ \\
$\mathrm{P}_{1} \mathrm{~B}_{0}$ & $0,31 \mathrm{~b}$ & $8,71 \mathrm{a}$ & $259,60 \mathrm{a}$ \\
$\mathrm{P}_{1} \mathrm{~B}_{1}$ & $0,26 \mathrm{a}$ & $8,23 \mathrm{a}$ & $245,58 \mathrm{a}$ \\
$\mathrm{P}_{2} \mathrm{~B}_{0}$ & $0,34 \mathrm{c}$ & $11,37 \mathrm{~b}$ & $346,88 \mathrm{~b}$ \\
$\mathrm{P}_{2} \mathrm{~B}_{1}$ & $0,32 \mathrm{bc}$ & $12,07 \mathrm{~b}$ & $321,76 \mathrm{~b}$ \\
$\mathrm{P}_{3} \mathrm{~B}_{0}$ & $0,35 \mathrm{bc}$ & $13,79 \mathrm{~b}$ & $355,21 \mathrm{~b}$ \\
$\mathrm{P}_{3} \mathrm{~B}_{1}$ & 0,03 & 2,08 & 33,40 \\
\hline BNT 5 \% & & & \\
\hline
\end{tabular}

Keterangan : Angka-Angka yang diikuti oleh huruf yang sama pada kolom yang sama berarti tidak berbeda nyata pada uji BNT taraf $5 \%$

\section{Kadar P-Tersedia}

Perlakuan pupuk Kompos dan NPK memberikan pengaruh yang nyata terhadap kadar P-tersedia disebabkan pupuk Ponska memberikan sumbangan hara $\mathrm{P}$ kedalam tanah sebesar $15 \%$ dan pupuk Kompos memberikan sumbangan hara $\mathrm{P}$ sebesar 0,38 $\%$, sehingga pupuk kompos dan pupuk NPK 
I GUSTI PUTU RATNA ADI DAN I NYOMAN PUJA. Peningkatan Produktivitas Tanaman Padi...

secara bersama-sama mendukung pupuk Kompos (236,10 ppm). Hasil ketersediaan P-tersedia di dalam tanah. Hal penelitian ini sesuai dengan hasil penelitian ini dapat terlihat perlakuan $150 \%$ Hermawan, (2002; dalam Rachman dan Idris, rekomendasi NPK dan 5 ton Kompos/ha 2008) bahwa pemberian bahan organik dan memberikan kadar P-tersedia tertinggi yaitu pupuk anorganik dapat meningkatkan $\mathrm{N}$-total sebesar 13,79 ppm dan terendah terdapat dan P-tersedia dan K-tersedia di dalam tanah. pada perlakuan $50 \%$ rekomendasi NPK dan tanpa pupuk kompos (8,21 ppm). Hasil penelitian ini sesuai dengan hasil penelitian Hermawan, (2002; dalam Rachman dan Idris, 2008) bahwa pemberian bahan organik dan pupuk anorganik dapat meningkatkan $\mathrm{pH}$ tanah, N-total dan P-tersedia dan K-tersedia di dalam tanah.

\section{Kadar K-Tersedia}

Perlakuan pupuk Kompos dan pupuk NPK memberikan pengaruh yang nyata terhadap kadar K-tersedia disebabkan pupuk kompos mengandung hara $\mathrm{K}_{2} \mathrm{O}$ sebesar 1,17 $\%$ dan pupuk NPK Ponska mengandung 15 $\%$ K. sehingga pupuk Kompos dan pupuk NPK secara bersama-sama memberikan sumbangan hara K-tersedia kedalam tanah. Hal ini dapat terlihat perlakuan $150 \%$ rekomnedasi NPK dan 5 ton Kompos/ha memberikan kadar K-tersedia tanah tertinggi yaitu 355,21 ppm dan terendah terdapat pada perlakuan $50 \%$ rekomendasi NPK dan tanpa

\section{Parameter Tanaman}

Hasil analisis statistik menunjukkan bahwa pemeberian pupuk Kompos dan NPK memberikan pengaruh yang tidak nyata baik secara tunggal mapun interaksi terhadap jumlah anakan per rumpun dan berat jerami kering per $\mathrm{m}^{2}$, sedangkan terhadap berat gabah berisi kering per $\mathrm{m}^{2}$ menunjukkan berpengaruh nyata. Hasil jumlah anakan, berat jerami kering per $\mathrm{m}^{2}$ dan berat gabah per $\mathrm{m}^{2}$ akibat perlakuan pupuk Kompos dan pupuk NPK disajikan pada Tabel 3. 
Tabel 3. Parameter Tanaman akibat pengaruh pupuk organik dan anorganik

\begin{tabular}{|c|c|c|c|}
\hline \multirow[b]{2}{*}{ Perlakuan } & \multicolumn{3}{|c|}{ Parameter tanaman } \\
\hline & $\begin{array}{l}\text { Jumlah Anakan } \\
\text { per rumpun (bt) }\end{array}$ & $\begin{array}{l}\text { Berat Gabah Jerami } \\
\text { Kering per } \mathrm{m}^{2}(\mathrm{~kg})\end{array}$ & $\begin{array}{l}\text { Berat Gabah berisi } \\
\text { Kering per } \mathrm{m}^{2}(\mathrm{~kg})\end{array}$ \\
\hline \multicolumn{4}{|l|}{ Pupuk Kompos (B) } \\
\hline $\mathrm{B}_{0}$ & $24,00 \mathrm{a}$ & $1,72 \mathrm{a}$ & $0.71 \mathrm{a}$ \\
\hline $\mathrm{B}_{1}$ & $26.33 \mathrm{a}$ & $1,77 \mathrm{a}$ & $0.83 \mathrm{~b}$ \\
\hline BNT $5 \%$ & ns & ns & 0,06 \\
\hline \multicolumn{4}{|l|}{ Pupuk NPK (P) } \\
\hline $\mathrm{P}_{1}$ & $24.50 \mathrm{a}$ & $1.69 \mathrm{a}$ & $0.71 \mathrm{a}$ \\
\hline $\mathrm{P}_{2}$ & $25.75 \mathrm{a}$ & $1.79 \mathrm{a}$ & $0.75 b$ \\
\hline $\mathrm{P}_{3}$ & $25.25 \mathrm{a}$ & $1.76 \mathrm{a}$ & $0.85 c$ \\
\hline BNT $5 \%$ & ns & ns & 0,08 \\
\hline \multicolumn{4}{|l|}{ Interaksi B x P } \\
\hline $\mathrm{P}_{1} \mathrm{~B}_{0}$ & $23.75 \mathrm{a}$ & $1.75 \mathrm{a}$ & $0.69 \mathrm{a}$ \\
\hline $\mathrm{P}_{1} \mathrm{~B}_{1}$ & $25.25 \mathrm{a}$ & $1.62 \mathrm{a}$ & $0.72 \mathrm{ab}$ \\
\hline $\mathrm{P}_{2} \mathrm{~B}_{0}$ & $25.00 \mathrm{a}$ & $1.67 \mathrm{a}$ & $0.70 \mathrm{ab}$ \\
\hline $\mathrm{P}_{2} \mathrm{~B}_{1}$ & $26.50 \mathrm{a}$ & $1.90 \mathrm{a}$ & $0.80 \mathrm{~b}$ \\
\hline $\mathrm{P}_{3} \mathrm{~B}_{0}$ & $23.25 \mathrm{a}$ & $1.75 \mathrm{a}$ & $0.74 \mathrm{ab}$ \\
\hline $\mathrm{P}_{3} \mathrm{~B}_{1}$ & $27.25 \mathrm{a}$ & $1.78 \mathrm{a}$ & $0.96 \mathrm{c}$ \\
\hline BNT $5 \%$ & $\mathrm{~ns}$ & $\mathrm{~ns}$ & 0,11 \\
\hline
\end{tabular}

Keterangan : Angka-Angka yang diikuti oleh huruf yang sama pada kolom yang sama berarti tidak berbeda nyata pada uji BNT taraf $5 \%$

\section{Jumlah Anakan per Rumpun}

Perlakuan pupuk Kompos memberikan pengaruh yang tidak nyata terhadap jumlah anakan per rumpun disebabkan pupuk kompos merupakan pupuk organik yang ketersediaan unsur hara relatif lambat dan kisaran dosis yang diberikan kurang lebar sehingga berpengaruh terhadap pertumbuhan jumlah anakan per rumpun yang tidak nyata. Hal ini dapat terlihat pada perlakuan 5 ton Kompos/ha menghasilkan jumlah anakan per rumpun sebanyak 26,33 batang dan berbeda tidak nyata dengan perlakuan tanpa pupuk Kompos (24,0 batang). Penambahan bahan organik dapat membantu penyediaan unsur hara dalam tanah terutama $\mathrm{N}$, dimana unsur $\mathrm{N}$ merupakan kunci keberhasilan produksi tanaman. Hal ini sesuai dengan Zulkarnain et al. (2013) bahwa pemberian pupuk organik pada tanah yang kandungan C-organik dan $\mathrm{N}$-total rendah dapat meningkatkan hasil tanaman tebu.

Perlakuan pupuk NPK memberikan pengaruh yang tidak nyata terhadap jumlah anakan per rumpun disebabkan dengan 
I GUSTI PUTU RATNA ADI DAN I NYOMAN PUJA. Peningkatan Produktivitas Tanaman Padi...

pemberian $50 \%$ rekomendasi NPK telah mencukup kebutuhan tanaman untuk menumbuhkan jumlah anakan padi sesuai dengan potensi genetik. Suprihatno et al (2009) menyatakan berdasarkan deskripsi varietas padi IR 64 memiliki jumlah anakan berkisar 20 - 35 batang/rumpun. Pada penelitian ini perlakuan pupuk NPK berpengaruh tidak nyata terhadap jumlah anakan per rumpun (fase pertumbuhan) disebabkan factor varietas padi. Hal ini dapat terlihat perlakuan pemberian $100 \%$ rekomendasi pupuk NPK menghasilkan jumlah anakan per rumpun tertinggi yaitu 25.75 batang, kemudian menurun berbeda tidak nyata pada perlakuan $100 \%$ rekomendasi NPK (25.25 batang) dan terendah terdapat pada perlakuan 50\% rekomendasi NPK (24,50 batang).

\section{Berat Jerami Kering Oven per $\mathbf{m}^{2}$}

Perlakuan pupuk kompos memberikan pengaruh yang tidak nyata terhadap berat jerami kering oven per $\mathrm{m}^{2}$ disebabkan pupuk kompos ketersediaan unsur hara relative lambat, dan kisaran dosis yang diberikan kurang lebar sehingga berpengaruh terhadap pertumbuhan tanaman di atas tanah yang ditunjukkan berat jerami padi. Hal ini didukung dari hasil pengamatan jumlah anakan padi bahwa perlakuan pupuk kompos berbeda tidak nyata dengan tanpa pemberian kompos. Jumlah anakan berhubungan langsung dengan berat jerami kering yaitu semakin banyak jumlah anakan maka semakin besar berat jerami kering dan sebaliknya. Hasil penelitian didapatkan perlakuan pemberian 5 ton kompos/ha menghasilkan berat jerami kering oven per $\mathrm{m}^{2}$ sebesar $1,77 \mathrm{~kg}$ dan berbeda tidak nyata dibandingkan tanpa pupuk kompos (1,72 $\mathrm{kg})$.

Perlakuan pupuk NPK memberikan pengaruh yang tidak nyata terhadap berat jerami kering oven $\mathrm{m}^{2}$ disebabkan pemberian $50 \%$ rekomendasi NPK telah mencukupi kebutuhan tanaman untuk pertumbuhan tanaman padi pada fase vegetative sehingga menunjukkan perbedaan yang tidak nyata antara perlakuan. Hasil penelitian menunjukkan pemberian 100\% pupuk NPK memberikan berat jerami kering oven per $\mathrm{m}^{2}$ tertinggi yaitu $1,79 \mathrm{~kg}$, kemudian menurun berbeda tidak nyata pada perlakuan $150 \%$ remomendasi NPK $(1,76$ $\mathrm{kg}$ ) dan terendah pada $50 \%$ rekomendasi NPK $(1,69 \mathrm{~kg})$.

\section{Berat Gabah Berisi Kering Oven per $\mathbf{m}^{2}$}

Perlakuan pemberian pupuk kompos dan NPK memberikan pengaruh yang nyata terhadap berat gabah kering oven per $\mathrm{m}^{2}$ 
disebabkan pupuk dan NPK secara bersamasama meningkatkan kesuburan tanah dan meningkatkan hasil tanaman padi. Pupuk Kompos menyediakan unsur hara relatif lambat dan pada saat fase generatif tanaman unsur hara dari kompos telah tersedia, sehingga tanaman dapat tumbuh dan berkembang dengan lebih baik dan menghasilkan berat gabah berisi yang lebih tinggi. Menurut Ezward et al. (2017) penggunaan pupuk kompos jerami padi akan memberikan unsur hara yang dibutuhkan tanaman bukan hanya unsur hara makro, tetapi juga unsur hara mikro. Menurut Samekto (2006), pupuk kompos membantu tanah yang miskin hara menyediakan unsur hara yang dibutuhkan tanaman dengan lebih baik, memperbaiki tanah menjadi lebih gembur sehingga akar tanaman dapat tumbuh dengan baik dan dapat melaksanakan fungsinya dalam menyerap unsur hara yang dibutuhkan tanaman dengan lebih optimal. Demikian juga, pemberian pupuk NPK dapat meningkatkan kadar $\mathrm{N}, \mathrm{P}$ dan $\mathrm{K}$ tanah dan dapat meningkatkan pertumbuhan dan perkembangan tanaman. Hardjowigeno (2003) menyatakan penggunaan pupuk majemuk NPK akan memberikan sumbangan unsur hara yang cukup besar sehingga dapat membantu meningkatkan pertumbuhan tanaman. Hal ini dapat dilihat pada perlakuan $150 \%$ rekomendasi NPK dan 5 ton kompos/ha menghasilkan berat gabah berisi per $\mathrm{m}^{2}$ tertinggi yaitu $0,96 \mathrm{~kg}$ atau meningkat $39,13 \%$ dibandingkan dengan perlakuan $50 \%$ rekomendasi NPK dan tanpa kompos $(0,69 \mathrm{~kg})$.

\section{SIMPULAN}

Berdasarkan hasil penelitian pengaruh pupuk organik dan anorganik terhadap sifat kimia tanah dan hasil padi sawah, maka dapat disimpulkan hah-hal sebagai berikut :

1. Kombinasi 5 ton pupuk kompos/ha dan $150 \%$ rekomendasi NPK dapat menghasilkan kadar N-total, kadar Ptersedia dan K-tersedia berturut-turut $0,35 \%, 13,79$ ppm dan 355,21 ppm lebih tinggi secara nyata dibandingkan dengan kombinasi 50\% rekomendasi NPK dan tanpa kompos yaitu berturutturut 0,26\% 8,21 ppm dan 236,10 ppm

2. Kombinasi 5 ton pupuk kompos/ha dan $150 \%$ dapat menghasilkan gabah berisi kering oven per $\mathrm{m}^{2}$ dari $0,69 \mathrm{~kg}$ atau meningkat sebesar $39,13 \%$ dibandingkan dengan kombinasi 50\% rekomendasi NPK dan tanpa kompos $(0,96 \mathrm{~kg})$.

3. Kombinasi ton pupuk kompos memberikan pengaruh yang tidak nyata 
I GUSTI PUTU RATNA ADI DAN I NYOMAN PUJA. Peningkatan Produktivitas Tanaman Padi...

terhadap jumlah anakan per rumpun dan berat jerami per $\mathrm{m}^{2}$.

\section{DAFTAR PUSTAKA}

Ezward. C., E. Indrawanis, Seprido dan Mashadi. 2017. Peningkatan Produktivitas melalui Teknik Budidaya dan Pupuk Kompos Jerami pada Budidaya Padi (Oryza sativa. L.). Jurnal Agrosains dan Teknologi. Vol. $2(1): 52-67$.

Hardjowigeno, S. 2003. Ilmu Tanah . Akademika Pressindo. Bogor:

Kasniari, DN dan A.A.N. Supadma. 2007. Pengaruh pemberian beberapa dosis pupuk $(\mathrm{N}, \mathrm{P}, \mathrm{K})$ dan jenis pupuk alternative terhadap hasil tanaman padi (Oryza sativa L.) dan kadar N, P, K inceptisol Selemadeg, Tabanan. Agritrop 24 (6) : 168 - 176.

Kaya. E. 2014. Pengaruh Pupuk Organik dan Pupuk NPK terhadap $\mathrm{pH}$ dan Ktersedia Tanah serta Serapan-K, Pertumbuhan dan Hasil Padi Sawah. Buana Sains Vol. 14 (2) : 113 - 122

Suprihatno, B., Aan A. Daradjat, Satoto, I N. Widiarta, Agus Setyono, S. Dewi Indrasari, Ooy S. Lesmana dan Hasil Sembiring. 2009. Deskripsi Varietas Padi. Balai Besar Penelitian Tanaman Padi. Balai Penelitian dan Pengemangan Pertanian Departemen Pertanian. Sukabumi.

Rachman, Idris Abd. Sri Djuniwati dan Romarudin Idris. 2008. Pengaruh bahan organik dan pupuk NPK terhadap serapan hara dan produksi jagung di Inceptisol Ternate. Jurnal Tanah dan Lingkungan, Vol. 10, No. 1 : 7 - 13

Wasis. B. dan Nuri Fathia. 2010. Pengaruh Pupuk NPk Dan Kompos Terhadap Pertumbuhan Semai Gmelina (Gmelina Arborea Roxb.) Pada Media Tanah
Bekas Tambang Emas (Tailing). Jurnal Ilmu Pertanian Indonesia, Vol. 16 (2) : 123-129.

Wahyuni E.S., Saiful, Endang dan W. Pudjiastutik. 2015. Pengaruh Penggunaan Pupuk NPK terhadap Produksi Padi (Oryza sativa L.) Varietas Ciherang. Jurnal Bioshell Vol. 04 (1) : 233 - 242.

Zulkarnain, M, Budi Prasetya dan Soemarno1. 2013. Pengaruh Kompos, Pupuk Kandang, dan Custom-Bio terhadap Sifat Tanah, Pertumbuhan dan Hasil Tebu (Saccharum officinarum L.) pada Entisol di Kebun Ngrangkah-Pawon, Kediri. Indonesian Green Technology Journal.Vol. (1) : 45 $-52$. 